\title{
Prevalence of depression, anxiety and stress among male secondary school students in Arar city, Saudi Arabia, during the school year 2018
}

\author{
Shaher Falah Alenazi ${ }^{1}$, Sabry Mohamed Hammad ${ }^{2}$, Amal Elwan Mohamed $^{3}$
}

${ }^{1}$ M.B.B.S, Resident in Saudi Board of Family Medicine, Joint Program of Saudi Board of Family Medicine, Arar City, Northern Borders Region, Saudi Arabia

${ }^{2}$ MD., Professor of Public Health and Community Medicine, Faculty of Medicine, Mansoura University, Mansoura,Egypt, consultant of Public Health \& Community Medicine, Northern Borders General Health Affairs, Saudi Arabia

${ }^{3}$ MD., Lecturer of Public Health, Faculty of Medicine, Zagazig University, Zagazig, Egypt, Consultant of Public Health, Saudi Board of Family Medicine, Northern Borders, Arar City, Saudi Arabia

\section{Type of article: Original}

\begin{abstract}
Background: Adolescence is characterized by rapid psychological changes. No data are available about psychological disorders among adolescents in the Northern Borders region of Saudi Arabia.

Objective: To determine the prevalence of depression, anxiety, and stress and its association with some risk factors among male secondary school students in Arar city; the capital city of Northern Borders, Saudi Arabia.

Methods: A cross-sectional study was conducted during the second semester of the school year 2017-2018. A sample of 406 male secondary school students was selected through a multistage cluster sampling technique. Out of 12 secondary schools, four schools were selected randomly then one class from each grade was also selected randomly. The participants were asked to complete a self-reported Arabic version of the Depression, Anxiety and Stress Scale (DASS-42). The data were analyzed by SPSS version 20, using descriptive statistics and Chi-square test of independence. A p-value of 0.05 or less was considered, statistically significant.

Results: The prevalence of depression, anxiety, and stress among 375 valid respondents was $56.3 \%, 56 \%$, and $41.9 \%$ respectively. The majority of symptoms were mild to moderate in severity. Out of all participants, $69.3 \%$ had at least one of the studied disorders; $50.9 \%$ had at least two disorders, and $33.9 \%$ had all the three disorders. The scores of depression, anxiety, and stress were positively and significantly correlated $(r=0.7 \mathrm{p}=0.001)$. History of the death of a close family member, family financial difficulties and smoking were significant risk factors for the development of any of the three studied disorders $(\mathrm{p}=0.019, \mathrm{p}=0.012, \mathrm{p}=0.001$ respectively).

Conclusion: The prevalence of depression, anxiety, and stress was high among male secondary school students in Arar city, KSA. Further in-depth national studies are needed to explore the problem and all possible risk factors. Also, strategies are needed to be developed to early detect these psychological disorders and prevent its progression among adolescents.
\end{abstract}

Keywords: Depression, Students, Anxiety, Stress, Arar, Saudi Arabia

\section{Introduction}

Adolescence is a crucial phase in life, characterized by rapid and profound physical, intellectual, emotional, and psychological changes (1), as well as the development of healthy or risky behaviors that can last a lifetime. The presence of psychiatric disorders like depression, anxiety, and stress at this stage of life can lead to poor academic performance, lack of communication with friends and family members, substance abuse, homicidal ideation and suicidal tendency (2). Worldwide, 10-20\% of children and adolescents experience mental disorders. The majority of

\section{Corresponding author:}

Dr. Shaher Falah Alenazi, Tel: +966.534068219, Email: shaher.dr25@hotmail.com

Received: November 04, 2018, Accepted: February 10, 2019, Published: June 2019

iThenticate screening: February 05, 2019, English editing: February 11, 2019, Quality control: April 25, 2019

This article has been reviewed / commented by three experts

Ethics approval: Northern Borders General Health Affairs (Ref: 39/3)

(C) 2019 The Authors. This is an open access article under the terms of the Creative Commons Attribution-NonCommercialNoDerivs License, which permits use and distribution in any medium, provided the original work is properly cited, the use is non-commercial and no modifications or adaptations are made. 
symptoms of mental disorders in adults began in childhood and adolescence $(3,4)$. The prevalence rates of specific disorders like depression, anxiety, and stress (DAS) are growing among adolescents (5). In the USA and Australia, $20 \%$ of teenagers suffer from mental health problems $(6,7)$. In Arab countries, data are limited regarding this age group, the prevalence of mental disorders among adolescents may reach $48 \%$ (8). In India, a study reported that the prevalence of depression, anxiety, and stress among secondary school students was $19.5 \%, 24.4 \%$, and $21.1 \%$, respectively (9). In Malaysia, higher figures are reported by the study of Abdul Latiff et al. (2017), among secondary school students, who found that $46 \%$ had depression symptoms, followed by anxiety symptoms (59.1\%) and stress symptoms (38.1\%) (10). In the Eastern Mediterranean Region, the estimated prevalence of child and adolescent mental disorders was $10 \%-36 \%$, which is either similar to or significantly higher than global estimates (11). In Abha, Saudi Arabia, the study of Al-Gelban on Saudi secondary school boys stated that more than one-third of the participants (38.2\%) had depression, while 48.9\% had anxiety and 35.5\% had stress. Moreover, 59.4\% of the participants had at least one of the three disorders, $40.7 \%$ had at least two, and $22.6 \%$ had all the three disorders (12). At present, there is a lack of data on psychological problems among Saudi male adolescents, especially in the Northern Borders region. This study aims to determine the prevalence of depression, anxiety, and stress symptoms among male secondary school students in Arar city, Northern Borders region, KSA, and its relation to some risk factors.

\section{Material and Methods}

\subsection{Study design and time period}

A cross-sectional study was conducted in male secondary schools in Arar city, Northern Borders region, Saudi Arabia. Data were collected during the second semester of the academic year 2017-2018.

\subsection{Participants}

There are 12 secondary schools for boys in Arar city, Northern Borders Region of Saudi Arabia. The total number of secondary school male students in Arar city during the 2017-2018 academic years was 5,780 boys.

\subsection{Selection criteria}

Inclusion criteria were: 1) male gender, 2) adolescent age, 3) resident in Arar city, 4) Saudis, and non-Saudis, and 5) regular students. Students who had hearing limitations or limited intellectual capabilities were excluded from the study.

\subsection{Sampling}

\subsubsection{Sample size}

The sample size was calculated using the formula " $n=\left(Z_{\alpha} / d\right)^{2} \times P(1-P)$ " (13), where $n$ is a sample size, $Z$ is the confidence interval taken as $1.96, \alpha$ is taken as 0.05 and $\mathrm{P}$ is the probability in this study considered according to previous study which reported that $59.4 \%$ of male students of secondary schools in Saudi Arabia had at least one psychological disorder (12). The minimum sample size calculated was 369 . About $10 \%$ of the sample size was added to compensate for any absentees and last-minute refusals to participate in the study. The total sample size achieved for the study was 406.

\subsubsection{Sampling method}

The sample of students was selected through a multistage cluster sampling technique. Out of 12 secondary schools for boys in Arar, four schools were randomly selected. Each secondary school has three teaching levels, which represent the $10^{\text {th }}, 11^{\text {th }}$, and $12^{\text {th }}$ years of education. Then one classroom from each grade level was selected randomly.

\subsection{Measures and instruments}

All students in the selected classes were subjected to the Arabic version of the self-reported and validated DASS-42 questionnaire along with a questionnaire for collection of some socio-demographic data and presence of chronic illness. The DASS-42 is a 42-item questionnaire developed by Lovibond \& Lovibond (14), to measure the symptoms of depression, anxiety, and stress. Each of the three scales contains 14 items. "Respondents were asked to use the 4-point severity/frequency scales to rate the extent to which they have experienced each state over the past week, $(0=$ did not apply to me at all, $1=$ applied to me to some degree, $2=$ applied to me to a considerable degree, or a good part of time and 3 = applied to me very much, or most of the time)". Questionnaires were collected and checked for completeness and consistency. Incomplete questionnaires were excluded from the analysis. 


\subsection{Ethical Consideration}

All the procedures in this study were in conformity with the Declaration of Helsinki. The research was approved from the ethical research committee of Northern Borders General Health Affairs (Ref: 39/3) and from General Directorate of Education. School directors and students were oriented about the study through an educational session, and verbal informed consent was taken. They were assured that collected data would be treated with high confidentiality and personal identifying information would not be published.

\subsection{Statistical Analysis}

Data were analyzed using IBMC SPSSC Statistics version 20 (IBMC Corp., Armonk, NY, USA). Chi-square test of independence was used and a $\mathrm{p}$-value of $\leq 0.05$ was considered statistically significant.

\section{Results}

The total sample size of the study was 406. Seven students were absent, and eleven refused to participate in the study. Thirteen questionnaires were incomplete and were excluded. Therefore, the total number of valid questionnaires was 375 . The mean age of the respondents was $16.8 \pm 0.8$ with a range of 16-19 years. Table 1 shows that a high prevalence of symptoms of depression, anxiety, and stress among male secondary students in Arar city, Northern Borders Region, Saudi Arabia (56.3\%, 56.0\%, 41.9\% respectively). Nearly two-thirds of students had all three disorders. The majority of symptoms of depression, anxiety, and stress were mild to moderate. Table 2 reveals that depression, anxiety, and stress among studied students were positively and significantly correlated. Table 3 shows that the prevalence of psychological disorders among secondary school boys did not differ significantly according to their socio-demographic characteristics and medical condition except for the death of a close family member, family financial difficulties and smoking. Students with a history of: the death of a close family member, current smoking and family financial difficulties were more likely to complain of psychological disorders than those without this history.

Table 1. Percentage of different psychological traits among male secondary school students, Arar city, Saudi Arabia ( $\mathrm{n}=375$ )

\begin{tabular}{|l|l|l|l|}
\hline Psychological trait & $\mathrm{n}$ & $\%$ \\
\hline \multirow{4}{*}{ Depression } & Normal & 164 & 43.7 \\
\cline { 2 - 4 } & Mild & 55 & 14.7 \\
\cline { 2 - 4 } & Moderate & 85 & 22.7 \\
\cline { 2 - 4 } & Severe & 43 & 11.5 \\
\cline { 2 - 4 } & Extremely severe & 28 & 7.4 \\
\hline \multirow{5}{*}{ Anxiety } & Normal & 165 & 44.0 \\
\cline { 2 - 4 } & Mild & 44 & 11.7 \\
\cline { 2 - 4 } & Moderate & 82 & 21.9 \\
\cline { 2 - 4 } & Severe & 48 & 12.8 \\
\cline { 2 - 4 } & Extremely severe & 36 & 9.6 \\
\hline Stress & Normal & 218 & 58.1 \\
\cline { 2 - 4 } & Mild & 51 & 13.6 \\
\cline { 2 - 4 } & Moderate & 67 & 17.9 \\
\cline { 2 - 4 } & Severe & 31 & 8.3 \\
\cline { 2 - 4 } & Extremely severe & 8 & 2.1 \\
\hline \multirow{5}{*}{ Had at least one psychological } & trait & 260 & 69.3 \\
\hline Had two psychological traits & Depression \& anxiety & 168 & 44.8 \\
\cline { 2 - 4 } & Depression \& stress & 138 & 36.8 \\
\hline & Stress \& anxiety & 139 & 37.1 \\
\hline \multirow{3}{*}{ Had all the three psychological traits } & 127 & 33.9 \\
\hline Had no psychological traits & & 30.7 \\
\hline
\end{tabular}

Table 2. Correlation between depression, anxiety, and stress among male secondary school students, Arar city, Saudi Arabia

\begin{tabular}{|l|l|l|}
\hline Psychological trait & $\mathrm{r}^{*}$ & $\mathrm{p}$-value \\
\hline Depression \& anxiety & 0.71 & $0.001^{* *}$ \\
\hline Depression \& stress & 0.75 & $0.001^{* *}$ \\
\hline Anxiety \& stress & 0.75 & $0.001^{* *}$ \\
\hline
\end{tabular}

* Pearson's Correlation Coefficient; ** Significant at $\mathrm{p}<0.001$ 
Table 3. Relation between psychological traits and some associated risk factors

\begin{tabular}{|c|c|c|}
\hline Characteristic & Odds ratio & p-value \\
\hline $\begin{array}{c}\text { School year } \\
-1^{\text {st }} \\
-2^{\text {nd }} \\
\text { - } 3^{\text {rd }}\end{array}$ & $\begin{array}{l}\mathrm{R} \\
1.7(0.99-2.9) \\
1.46(0.86-2.5)\end{array}$ & $\begin{array}{l}0.054 \\
0.16\end{array}$ \\
\hline $\begin{array}{c}\text { The divorce between parents } \\
\text { - Yes } \\
\text { - No }\end{array}$ & $\begin{array}{l}\mathrm{R} \\
1.27(0.42-3.87)\end{array}$ & 0.677 \\
\hline $\begin{array}{c}\text { Death of close family member } \\
\text { - Yes } \\
\text { - No }\end{array}$ & $\begin{array}{l}2.47(1.16-5.23) \\
\mathrm{R}\end{array}$ & $0.019^{*}$ \\
\hline $\begin{array}{c}\text { Financial difficulties } \\
\text { - Yes } \\
\text { - No }\end{array}$ & $\begin{array}{l}4.42(1.3-8.97) \\
\mathrm{R}\end{array}$ & $0.012^{*}$ \\
\hline $\begin{array}{c}\text { Repeat year after failure } \\
\text { - Yes } \\
\text { - No }\end{array}$ & $\begin{array}{l}1.49(0.4-5.5) \\
\mathrm{R}\end{array}$ & 0.548 \\
\hline $\begin{array}{c}\text { Smoking } \\
\bullet \quad \text { Yes } \\
\text { - No }\end{array}$ & $\begin{array}{l}3.52(1.94-6.4) \\
\mathrm{R}\end{array}$ & $0.001 * *$ \\
\hline $\begin{array}{c}\text { Chronic or serious disease } \\
\text { - Yes } \\
\text { - No }\end{array}$ & $\begin{array}{l}2.13(0.79-5.76) \\
\mathrm{R}\end{array}$ & 0.134 \\
\hline
\end{tabular}

\section{Discussion}

This was a cross-sectional study aimed to determine the prevalence of depression, anxiety, and stress and its association with some risk factors among male secondary school students in Arar city; the capital city of Northern Borders, Saudi Arabia. The present study found the prevalence of depression, anxiety, and stress in male secondary school students was high. This finding is quite higher than that reported in a study on secondary school boys in Abha, Asir region, Saudi Arabia, which found that depression, anxiety and stress were in $38.2 \%, 48.9 \%$ and $35.5 \%$ of studied students respectively (12). Another study done by Al-Gelban et al. on secondary school girls in Abha, Asir region, Saudi Arabia, reported a high prevalence of depression (41.5\%) and higher prevalence of anxiety and stress (66.2\% and 52.5\% respectively) (15). In Riyadh city, Raheel (2016) in her study on adolescent girls aged 1519 years in secondary schools, found that about $30 \%$ of the participants were depressed (16). Reporting symptoms of mental disorders is high among adolescents $(8,12,15)$. The information was obtained by a self-reported questionnaire. Studies based on self-reported questionnaires depend mainly on symptoms rather than psychiatric diagnosis, and give rise to a higher prevalence rate than others. Contrarily, in a study conducted in Taif city, Saudi Arabia, among schoolchildren and adolescents, it was found that $9.3 \%$ of the subjects were emotionally and/or behaviorally disturbed (17). In Oman, Afifi et al. (18), in their study on secondary school students, reported that the prevalence of depression was $17 \%$ (19\% for girls and $14.7 \%$ for boys) which is much lower than our findings. Our findings were also higher than that reported in an Indian study, which found the prevalence of stress, anxiety and depression among secondary school students were $21.1 \%, 24.4 \%$ and $19.5 \%$ respectively (9). A study conducted in Malaysia (10) among adolescents in secondary schools found the prevalence of depression (46\%) which was similar to our findings; however, the prevalence of anxiety and stress $(59.1 \%$ and $38.1 \%$ respectively) were slightly different from our results. The high prevalence rates of DAS in our study might be due to increasing academic and parental stress on Saudi male secondary school students due to social and cultural transformations in Saudi society. The students need to attain high scores to realize their parents' demands and expectations.

In the present study, $69.3 \%$ of the students had symptoms of at least one of the three studied disorders, $50.9 \%$ had at least two psychological disorders, and $33.9 \%$ had all three studied disorders. In agreement to these findings, a study in Abha city on secondary school girls reported similar findings (73.4\%, 50.1\%, and 35.5\% respectively) (15) and even higher than that reported by the study on secondary school boys in the same city $(59.4,40.7 \%$ and $22.6 \%$ respectively) (12). This very wide prevalence rate and observed variation are due to many factors, mainly the 
difference in case definition, the diversity of the screening tools, different cultures, methodology and sampling techniques.

Regarding the severity of the symptoms of depression, anxiety, and stress, they were mild to moderate in the majority of students in the present study. This finding is in consistency with the findings of other studies $(12,15$, 19, 20). The current study showed a significant positive correlation between the studied disorders (depression, anxiety, and stress). Depressive symptoms are associated with a high level of anxiety and inability to cope with life stressors. The three disorders are correlated with each other. This was in accordance with other studies $(12,15,19$, 21),

The recent death of a close family member had an effect on the development of psychological disorders (depression, anxiety, and stress) among young adolescents, as was seen in the present study. This finding is in line with study of Stikkelbroek et al., 2016 (22), which reported that internalizing problems of mental health increase in adolescents after family bereavement in comparison to non-bereaved. Also, it is in agreement with the finding of Bhasin et al., 2010, who pointed to the fact that special care and support is needed for students who have had recent adverse events of life such as death of a family member (23). In our study, male secondary school students with history of family financial difficulties were more than four times $(\mathrm{OR}=4.42$, CI: 1.3-8.97) likely to develop symptoms of DAS than those with no history; a finding in agreement with that reported by Sandal et al., 2017, who found that depression and stress were prevalent in participants who belong to poor families (24). Direct and indirect effects of economic deprivation or financial stress had an effect on the development of emotional, behavioral, and psychiatric problems. Poverty is a multidimensional phenomenon, including the inability to satisfy basic needs, lack of control over resources, lack of education and poor health (25). A systemic review study on the Association of Cigarette Smoking with Depression and Anxiety conducted by Mres et al., (2017), showed that nearly half the studies reported that depression and anxiety were associated with smoking behavior, while over a third stated that exposure to smoking was associated with later depression/anxiety (26). In the current study, non-smoking among subjects protected against having symptoms of DAS (OR=3.52, CI: 1.94-6.4). A similar finding was observed in the study conducted in Oman which reported that smokers were more likely to have depressive symptoms $(29.8 \%)$ than nonsmokers (16.6\%) (18).

In the present study, those with a history of chronic physical disease were nearly two times more likely to have symptoms of DAS, but the association was not significant ( $\mathrm{p}>0.05)$. On the other hand, Afifi et al., 2006, reported a significant association between the presence of chronic physical illness among adolescents and having depressive symptoms. Symptoms of DAS in children and adolescents increased with age $(24,27)$. The current study found that students with final grades were complaining of DAS symptoms twice as much, but this was not statistically significant. Children and adolescents who lived without parents exhibited higher levels of depressive symptoms than those who lived with parents around them (28). Also, depression is decreased by higher levels of parental care and lower levels of parental indifference and strong positive family relationships $(29,30)$. However, in our study, there was no significant association between having a history of divorce between parents and having symptoms of DAS. This might be explained by the small number of students with history of divorce between parents.

\section{Study limitations}

The dearth of research on adolescent psychological problems published in Arab countries, and the diversity of screening tools for DAS limited the chances for comparison of results. In addition, the use of a self- reported questionnaire might elicit inflated or false responses, especially in such a sensitive age group. The study was restricted to male students only, which prevented the determination of sex-specific prevalence rates. Also, it was a school-based study, which might, therefore, miss adolescents in the community who do not go to school.

\section{Conclusions}

The symptoms of depression, anxiety, and stress are quite high among male secondary school students in Arar city. There is a need for screening adolescents for mental health problems, also, to develop strategies to alleviate their stress. Early detection of these psychological disorders favors combating its progression to manifest disease and improve adolescents' quality of life. Both the family and the school authorities are required to be sensitive to the needs of adolescents for support and guidance. 


\section{Acknowledgments:}

The authors would like to acknowledge their sincere thanks to the Saudi Board of Family Medicine, a joint program. This study was done for partial fulfillment of the Saudi Board of Family Medicine. The authors would like to thank all the participating students for their co-operation and all school authorities for giving permission to conduct the study.

\section{Conflict of Interest:}

There is no conflict of interest to be declared.

\section{Authors' contributions:}

$\mathrm{Al}$ authors contributed to conception or design of the work. SFA performed the data acquisition. SMH and AEM performed the analysis or interpretation of data. SFA and AEM drafted the manuscript and all authors revised it before submission or during the review process. All authors are accountable for all aspects of the work

\section{References:}

1) American Academy of Pediatrics. Stages of Adolescence. 2015. Available from: https://www.healthychildren.org/English/agesstages/teen/Pages/Stages-of-Adolescence.aspx

2) Gregory AM, Caspi A, Moffitt TE, Koenin K, Eley TC, Poulton R. Juvenile mental health histories of adults with anxiety disorders. Am J Psychiatry. 2007; 164: 301-8. doi: 10.1176/ajp.2007.164.2.301. PMID: 17267794.

3) Jones P. Adult mental health disorders and their age at onset. Br J Psychiatry. 2013; 202(s54): s5-s10. doi: 10.1192/bjp.bp.112.119164. PMID: 23288502.

4) WHO. Maternal, newborn, child and adolescent health. 2017. Available from: http://www.who.int/maternal_child_adolescent/topics/adolescence/mental_health/en/

5) Institute for Health Metrics and Evaluation. The Global Burden of Disease: Generating Evidence, Guiding Policy. University of Washington, Seattle, WA, USA: IHME; 2013.

6) Merikangas KR, He J, Burstein M, Swanson SA, Avenevoli S, Cui L, et al. Lifetime Prevalence of Mental Disorders in US Adolescents: Results from the National Comorbidity Supplement (NCS-A). J Am Acad Child Adolesc Psychiatry. 2010; 49(10): 980-9. doi: 10.1016/j.jaac.2010.05.017. PMID: 20855043, PMCID: PMC2946114.

7) Bailey V, Baker AM, Cave L, Fildes J, Perrens B, Plummer J, et al. Australia's Youth Survey Report. Mission Australia's Youth Survey Report, 2016.

8) Al-Sughayr AM, Ferwana MS. Prevalence of mental disorders among high school students in National Guard Housing, Riyadh, Saudi Arabia. J Family Community Med. 2012; 19(1): 47-51. doi: 10.4103/22308229.94015. PMID: 22518359, PMCID: PMC3326771.

9) Kumar KS, Akoijam BS. Depression, Anxiety, and Stress Among Higher Secondary School Students of Imphal, Manipur. Indian Journal of Community Medicine. 2017; 42(2): 94-6. doi: 10.4103/ijcm.IJCM_266_15.

10) Abdul Latiff L, Tajik E, Ibrahim N, Abu Bakar AS, Shirin SSA. Psychosocial Problem and its Associated Factors Among Adolescents in the Secondary Schools in Pasir Gudang, Johor. Malaysian Journal of Medicine and Health Sciences. 2017; 13(1): 35-44.

11) World health organization. Maternal, child and adolescent mental health: challenges and strategic directions 2010-2015. WHO regional office for EMR regional Committee for the EM/RC57/3. Fiftyseventh Session Original: Arabic Agenda item 4(a); 2010.

12) Al-Gelban KS. Depression, anxiety, and stress among Saudi adolescent schoolboys. J R Soc Promote Health. 2007; 127(1): 33-7. PMID: 17319315.

13) Charan J, Biswas T. How to calculate sample size for different study designs in medical research? Indian $\mathrm{J}$ Psychol Med. 2013; 35(2): 121-6. doi: 10.4103/0253-7176.116232. PMID: 24049221, PMCID: PMC3775042.

14) Lovibond SH, Lovibond Pf. Manual for the Depression Anxiety Stress Scales. (2nd Ed) Sydney: Psychology Foundation; 1995.

15) Al-Gelban KS, Al-Amri HS, Mostafa OA. Prevalence of Depression, Anxiety, and Stress as Measured by the Depression, Anxiety, and Stress Scale (DASS-42) among Secondary School Girls in Abha, Saudi Arabia. Sultan Qaboos University Medical Journal. 2009; 9(2): 140-7. 
16) Raheel S. Depression and Associated Factors among Adolescent Females in Riyadh, Kingdom of Saudi Arabia, A Cross-sectional Study. Int J Prev Med. 2015; 6: 90. doi: 10.4103/2008-7802.165156. PMID: 26445637, PMCID: PMC4593237.

17) Abdel-Fattah MM, Asal AM, Al-Asmary SM, Al- Helali NS, Al-Jabban TM, Arafa MA. Emotional and Behavioral Problems among Male Saudi Schoolchildren and Adolescents Prevalence and Risk Factors. Ger J Psychiatr. 2004; 1: 1-9.

18) Afifi M, Al Riyami A, Morsi M, Al Kharusil H. Depressive symptoms among high school adolescents in Oman. Eastern Mediterranean Health Journal. 2006; 12(Supplement 2): 126-37. PMID: 17361684.

19) Bilgel N, Bayram N. The Epidemiology of Depression, Anxiety, Stress and Anger in Turkish High School Students. British Journal of Education, Society \& Behavioural Science. 2014; 4(9): 1153-70.

20) Kanagasabapathy S, Raj S. Depration, Anexiety and stress- a cross-sectional study in a cohort of school students from South India. J Evolution Med Dent Sci. 2017; 6(41).

21) Preeti B, Singh K, Kumar R. Study of Depression, Anxiety, and Stress Among School Going Adolescents. Indian Journal of Psychiatric Social Work. 2017; 8(1).

22) Stikkelbroek Y, Bodden DHM, Reitz E, Vollebergh WAM, van Baar AL. Mental health of adolescents before and after the death of a parent or sibling. Eur Child Adolesc Psychiatry. 2016; 25: 49-59. doi: 10.1007/s00787-015-0695-3. PMID: 25786705, PMCID: PMC4698293.

23) Bhasin SK, Sharma Rand Saini NK. Depression, Anxiety, and Stress among Adolescent Students Belonging to Affluent Families: A School-based Study. Indian Journal of Pediatrics. 2010; (77): 161-5.

24) Sandal RK, Goel NK, Sharma MK, Bakshi RK, Singh N, Kumar D. Prevalence of Depression, Anxiety, and Stress among school going adolescent in Chandigarh. Journal of Family Medicine and Primary Care. 2017; 6(2): 405-10.

25) Butler AC. Poverty and adolescent depressive symptoms. Am J Orthopsychiatry. 2014; 84(1): 82-94.

26) Fluharty M, Taylor AE, Grabski M, Munafò MR. The Association of Cigarette Smoking With Depression and Anxiety: A Systematic Review. Nicotine Tob Res. 2017; 19(1): 3-13.

27) Das JK, Salam RA, Lassi ZS, Khan MN, Mahmood W, Patel V, et al. Interventions for Adolescent Mental Health: An Overview of Systematic Reviews. J Adolesc Health. 2016; 59(4S): 49-60. doi: 10.1016/j.jadohealth.2016.06.020. PMID: 27664596, PMCID: PMC5026677.

28) Zgambo M, Kalembo F, Guoping H, Honghong W. Depression among Chinese children and adolescents: A review of the literature. Int J Child Youth Family Stud. 2012; 3: 442-57.

29) Liu YL. Parent-child interaction and children's depression: The relationships between parent-child interaction and children's depressive symptoms in Taiwan. J Adolesc. 2003; 26: 447-57.

30) Zhang Y, Li H, Zou S. Association between cognitive distortion, type D personality, family environment, and depression in Chinese adolescents. Depress Res Treat. 2011; 2011: 143045. doi: 10.1155/2011/143045. PMID: 21747993, PMCID: PMC3130968. 